Ankara Sağlık Hizmetleri Dergisi,

Cilt 16, Sayı 1, 2017

\title{
Şartsız Hayvan Anksiyete Testleri
}

\author{
Hasan ÇALIŞKAN ${ }^{1}$, Furat AKAT $T^{1}$, Nezahat ZALO ĞLU ${ }^{1}$ \\ ${ }^{1}$ Ankara Üniversitesi Tip Fakültesi Fizyoloji Anabilim Dall, Ankara,Türkiye \\ e-mail: hasanmonica@hotmail.com
}

\begin{abstract}
Özet
Anksiyete korku ve endişe gibi emosyonları içeren bir durumdur. Anksiyetenin altında yatan mekanizmayı anlamak, yeni tedavi seçenekleri oluşturmak amacıyla hayvan anksiyete testleri kullanılmaktadır. Bu derlemede şartsız anksiyete testi olarak sıklıkla kullanılan açık alan testi, yükseltilmiş artı labirent testi ve aydınlık karanlık kutusu testi incelenmiştir.
\end{abstract}

Anahtar Kelimeler: Açık alan testi, Anksiyete, Aydınlık karanlık kutusu, Yükseltilmiş artı labirent, Sartsız anksiyete testleri

\begin{abstract}
Anxiety is an emotional situation that include fear and apprehension. To understand the underlying mechanism of anxiety and in order to improve new therapeutic agents, the unconditioned animal anxiety tests are conducted. In this this review, open field test, elevated plus maze and light dark box tests are investigated which are unconditioned tests in general use.
\end{abstract}

Key Words: Anxiety, Elevated plus maze, Light dark box, Open field test, Unconditioned anxiety tests 


\section{Giriş}

Anksiyete korku ve endişe gibi emosyonları içeren durumdur. Anksiyete sırasında oluşan korku ve endişe için temel bazı beyin devreleri tanımlanmıştır. Endişe ile ilgili beyin devresi dorsolateral prefrontal korteks, striatum ve talamustan oluşur. Söz konusu devreninin aşırı uyarılması endişeye neden olmaktadır. Korku ile ilgili devreler ise amigdala bağlantılıdır. Bunlar amigdala ile hippokampus, amigdala ile lokus seruleus, amigdala ile parabrakial nükleus ve amigdala ile hipotalamus arasındaki beyin devreleridir (Stahl, 2015).

Anksiyetenin altında yatan mekanizmaları anlamak, yeni tedavi ajanları geliştirebilmek için hayvan anksiyete testleri sıklıkla kullanılmaktadır. Hayvan anksiyete testleri genel olarak şartlı ve şartsız olmak üzere iki başlık altında toplanmaktadır. Şartlı anksiyete testleri elektrik şoku gibi ağrılı uyaran içerebilirler. Son yıllarda artan bir şekilde şartlı anksiyete testlerinden uzaklaşılmakta ve daha doğal olan şartsız anksiyete testleri, araştırmacılar tarafından tercih edilmektedir. Bu derlemede şartsız anksiyete testlerinden en çok kullanılan açık alan testi, yükseltilmiş artı labirent ve aydınlık karanlık kutusu testi ele alınmıştır.

\section{Açık Alan Testi}

İlk kez 1934 yılında Hall tarafından sıçanlarda tanımlanmıştır. Yapılan ilk deneyde sıçanın açık alana konulmasıyla birlikte oluşan dışkılama sayısı ile ürkeklik arasındaki ilişki incelenmiştir (Hall, 1934).

Deneklerin alışık olduğu ortamdan alınarak yeni çevreye konulmaları, grup ya da sürüden ayrılma ve açık alana bırakılma anksiyeteye yol açmaktadır. Açık alan testini uygulama alanları farklı ebatlarda ve şekillerde olabilir. Araştırmacılar tarafından dairesel, dikdörtgen ve kare formları kullanılmıştır (Hall, 1934; Zimbardo, 1957; Soubrie, 1971). Bütün formlarında merkez bölge ve periferik bölge olmak üzere açık alan testinde iki bölge bulunur.

Deneye denek her zaman test düzeneğinde merkez bölgeye konularak başlanır. Anksiyetenin azalmasına bağlı olarak merkez bölgeye girme sayısı ve merkez bölgede geçen süre artar. Aksine anksiyete artışı ile periferik bölgede geçen süre artar. Açık alana konan hayvanlarda anksiyete artışına bağlı olarak sınırları belirli testin duvar ve köşelerine kaçma, periferde vakit geçirme isteği görülür. Bu davranışa thigmotaksis denir (Prut ve Belzung, 2003). Açık alan testinde anksiyete ölçümü ile ilgili birçok davranış (iki ayağı üzerine kalkma, kaşınma, gezinme v.b) ve parametre belirtilmiştir. Bunlardan en önemlilerinden birisi iki ayağı üzerine kalkma davranışıdır. Açık alana konan hayvanlarda yeni çevre hem merak uyandırmakta hem de anksiyeteye yol açmaktadır. Her iki duygunun çatışmasında merak duygusu daha ağır basması durumunda hayvan yeni çevreyi araştırma davranışı olarak iki ayağı üzerine kalkma davranışını yapmaktadır. İki ayağı üzerine kalkma davranışı açık alanın periferindeki duvardan destek alınarak yapılabileceği gibi duvar desteği olmadan da yapılabilir. iki ayağı üzerine kalkma davranışı dışında toplam gezinilen süre, bir bölmeyi katetme süre, merkez alanı terk etme süresi, hareketsiz geçirdiği süre, merkezde toplam hareket ettiği süre, merkeze giriş çıkış sayısı, periferde geçen süre, havayı koklama davranışı, kazıma, kaşınma, diş gıcırdatma, dışkılama miktarı ve ürinasyon varlığı da incelenmektedir. Açık alan testinde genel olarak bir kez ve beş dakika uygulanmasına karşın, farklı araştırmalarda on dakikaya kadar uygulanmaktadır (Walsh, 1976). Açık alan testi kullanılan hayvanın türü açınsından davranış testleri arasında en zengin olanıdır. Kedi, Köpek, gerbil, domuz, kobay, tavuk, primat, zebra balığ 1 , koyun, gelincik, fare ve sıçan olmak üzere çok farklı hayvan gruplarında uygulanmıştır (Ehrlich ve Burns, 1958;Candland ve Nagy, 1969; Martinek ve Lat, 1969; Oldham ve Morlock, 1970; Pedernera et al, 2010; Cagni et al, 2013; Mushtag et al, 2014; Bagewadi et al, 2015; Fiset et al, 2015; Meijer et al, 2015; Sayapina et al, 2015). 
Açık alan testi anksiyete testi olmasının dışında başka amaçlarla da kullanılmaktadır. 1977 yılında Porsolt ve arkadaşları tarafından geliştirilmiş depresyon testi olan zorunlu yüzme testiyle birlikte kombine uygulanmaktadır. Porsolt yüzmeye zorlanan sıçan ve farelerde belli bir süre sonra odun kütüğü gibi su içinde asılı kaldığını tanımlamıştır (Porsolt et al, 1977).

Pasif hareket olarak tanımladığı bu davranışın depresyondaki çaresizliğe denk geldiğini ve klinikte etkili olan antidepresanların bu süreyi kısalttığını göstermiş̦tir. Yaptığı çalışmada kafein gibi psikostimülantların da antidepresan gibi pasif süreyi kısalttığı, su içinde aktif hareketi arttırdığını gözlemlemiş̧ir. Bu durumu ortadan kaldırmak için sonradan yaptığı zorunlu yüzme testine açık alan testini eklemiştir. Kafein gibi psikostimülantların hem zorunlu yüzme testinde hem de açık alan testinde lokomotor aktivite artışı gözlenirken, antidepresanlarda sadece zorunlu yüzme testinde aktif hareket artışı bildirilmiştir. Daha sonra yapılan çalışmalarda yalancı antidepresan aktiviteyi göstermek ve yeni antidepresan ajan geliştirirken açık alan testi zorunlu yüzme testi ile kombine uygulanmıştır (Porsolt et al, 1978a; Porsolt 1978b).

Yalancı antidepresan etki göstermenin dışında açık alan testinin içine konan geometrik cisimler ile öğrenme testi olan obje tanıma testi olarak da kullanılabilir.

Bunların dişında yine bir depresyon modeli olan olfaktor bulbektomi ile oluşturulan depresyonda açik alan testinde hiperaktivite artışı gözlemlenir. Olfaktor bulbektomi yöntemi ile birlikte de bu nedenle birlikte uygulanmaktadır (Kalueff ve Tuohımaa, 2004).

\section{Yükseltilmiş Artı Labirent}

1955 yılında Montegomery tarafında y şeklinden oluşan bir form olarak tanımlanmıştır. Y şeklindeki formda iki açık kol içeren sistem yeni çevrenin ve açık yüksek kolların oluşturduğu anksiyete üzerine kurulmuştur (Montgomery, 1955). Daha sonra 1984 yılında Handley ve Mithani, 1985 yılında ise Pellow ve arkadaşları tarafından modifiye edilerek iki kapalı, iki açık koldan oluşmuştur. Yerden genellikle 50$70 \mathrm{~cm}$ yüksekliğinde artı şeklinde açık ve kapalı kollardan oluşan şekli oluşturulmuştur (Handley ve Mithani, 1984; Pellow et al, 1985). Rodentlerde doğal ve şartsız anksiyete oluşturmada en sik tercih edilen anksiyete testidir(Korte veDe Boer, 2003). Yükseltilmiş artı labirent testinde sıçan ya da fare açık alan testinde olduğu gibi merkez bölgeye konulur. Merkez bölge iki açık iki kapalı kolun kesiştiği bölgedir. Kafesinden alınan denekte yeni çevre ve yükseklik anksiyeteye yol açar (Arantes et al, 2013). Artan anksiteye bağlı olarak kapalı kolda geçen süre, kapalı kola girme sayısı, kapalı kolda geçen sürenin yüzdesi artar. Anksiyetenin azalmasına bağlı olarak da açık kolda geçen süre ve açık kola girme sayis1 artar.

Bunların dışında açık alan testinde olduğu gibi iki ayağı üzerine kalkma sayısı, kaşınma süresi, dışkılama sayısı gibi parametrelere de bakılır. Anksiyete testi dışında öğrenme testi ve madde bağımlılı̆̆ını doğrulama modeli olarak da kullanılmaktadır(Carobrez veBertoglio, 2005).

Açık alan testinde olduğu gibi lokomotor aktivitenin ölçülmesine rağmen araştırmalar arasında farklılık ve görüş birliği yoktur(Kumar et al, 2013). Bazı araştırmacılar toplam kola girme sayısını bazı araştırmacılar ise açık veya kapalı kola girme sayısını lokomotor aktivite olarak yorumlamaktadır.

Açık alan testi kadar tür zenginliği olmamakla birlikte sıçan, fare, gerbil, hamster ve sincapla yapılan çalışmalar mevcuttur (Wall ve Messier, 2001).

Tür, ırk, cinsiyet, östrus ve laktasyon evreleri, yaş, barındırma ve tutma koşulları, sirkadyan ritm, karanlık 1şıklı evre süresi, uygulama öncesi tutma veya enjeksiyon stresi, labirentin yüzeyi ve aydınlanma seviyesi deney sonucunu etkileyebilmektedir.

Yükseltilmiş artı labirente lietaratürde $\mathrm{x}$ labirent de denmektedir. Yükseltilmiş artı labirentden türemiş t labirent, sıfir labirent ve sabit olmayan yükseltilmiş artı labirent gibi formları bulunmaktadır(Bourin et al, 2007). 
Yükseltilmiş artı labirent bunların dışında açık alan testinde olduğu gibi sıklıkla depresyon testi olan zorunlu yüzme testi ile birlikte kullanılır. Depresyon ve anksiyetenin birlikte görülme sıklığı nedeniyle birlikte kullanılan bu iki testin parametreleri arasında korelasyon olduğu ve olmadığı yönünde çalışmalar da mevcuttur (Andreatini et al, 1999).

\section{Aydınlık Karanlık Kutusu Testi}

1980 yılında Crawley ve Goodwin tarafından tanımlanmıştır (Crawley ve Goodwin, 1980). İki eşit bölme ve aralarında geçişi sağlayan bölmeden oluşur. Gece aktif olan sıçan ve farelerde sıklıkla kullanılmaktadır. Yükseltilmiş artı labirent ve açık alan testinden sonra 3. En çok tercih edilen şartsız anksiyete testidir. Kafesinden alınan denekte yeni çevre ve 1șıklandırılmıș bölme anksiyeteye neden olmaktadır. Crawley ve Goodwin ilk yaptıkları çalışmalarda parametre olarak aydınlık ve karanlık bölme arasındaki geçiş sayısını hesaplamıştır. Daha sonra karanlık bölgede geçen süre ve aydınlık bölgede geçen süre de eklenerek modifiye edilmiştir(Belzung et al, 1987).

Genel olarak temel bazı parametreler incelenmektedir. Aydınlık alanda geçen süre, karanlık alanda geçen süre, aydınlık karanlık bölme arasında geçiş sayısı, aydınlık bölmeden karanlık bölmeye ilk geçiş süresi, kaşınma ve iki ayağı üzerine kalkma davranışı başlıcalarıdır.

Genel olarak anksiyolitik ajanlar aydınlık alanda geçen süreyi arttırmakta anksiyojenik ajanlar ise azaltmaktadır ( Imaizumi et al, 1994).

\section{Açık Alan Testi,Yükseltilmiş Artı Labirent ve Aydınlık Karanlık Kutusuna Genel Bakış}

Her üç test de davranış fizyologları, psikofarmakologlar ve psikiyatristler tarafindan sıklıkla kullanılmaktadır. Her üç testin araştırmacıya sağladığı birçok avantaj söz konusudur. Ucuz olması, doğal anksiyete oluşturması, kurulum basitliği önemli avantajlarıdır

Üç testte de yeni çevre anksiyete yol açarken ilaveten açık alan testinde açık alan korkusu, yükseltilmiş artı labirentte yükseklik, aydınlık karanlık kutusunda ışık eklenmektedir.

Her üç anksiyete testinde denek ortama alındığında otonomik sinir sistemi aktivitesi ile dışkılama ve işeme görülebilir. Deney bitiminde oluşan ürinasyon ve defakasyonun başka bir denek teste alınmadan önce alkollü bir solüsyonla silinmesi gerekmektedir. Ortamın sessiz olması ve 1şıklandırılmasına da özen gösterilmelidir.

Açık alan testinde lokomotor aktiviteyi incelemek yükseltilmiş artı labirente göre daha avantajlıdır. Yükseltilmiş artı labirentte araştırmacılar arası görüş birliği olmaması nedeniyle açık alan testi lokomotor aktivite incelemesinde daha kullanışlı gözükmektedir.

Açık alan testi ve yükseltilmiş artı labirent testleri sıklıkla 8:00-14:00 saatlerinde yapılmakla birlikte aydınlık karanlık kutusu testi karanlık evrede de yapılabilmektedir.

$\mathrm{Bu}$ nedenle her üç testin birlikte yapıldığı çalışmalarda açık alan testi ve yükseltilmiş artı labirent sırasıyla gündüz, aydınlık karanlık kutusu karanlık evrede yapılabilir.

Her üç testin yapıldığı sırada araştırmacının ortamda bulunması deneyi olumsuz etkileyebilir. $\mathrm{Bu}$ nedenle deney esnasında kamera ile kaydedilmesi gerekmektedir. Araştırmanın daha sonra video kayıtlarından analizi daha yararlı olacaktır. 


\section{Kaynaklar:}

Andreatini R, Bacellar LF Braz J. The relationship between anxiety and depression in animal models: a study using the forced swimming test and elevated plus-maze. Med Biol Res. 1999; 32(9):1121-6.

Arantes R, Tejada J, Bosco GG, Morato S, Roque AC. Mathematical methods to model rodent behavior in the elevated plus-maze. J Neurosci Methods. 2013; 220(2):141-8.

Bagewadı HG, Ak AK, Shivaramegowda RM. An Experimental Study to Evaluate the Effect of Memantine in Animal Models Anxiety in Swiss Albino Mice. J Clin Diagn Res. 2015; 9(8):1-5.

Belzung C, Misslin R, Vogel E, Dodd RH, Chapouthier G. Anxiogenic effects of methyl-betacarboline-3-carboxylate in a light/dark choice situation. Pharmacol Biochem Behav. 1987; 28(1): 2933.

Bourin M, Petit-Demoulière B, Dhonnchadha BN, Hascoet M (2007). Animal models of anxiety in mice. Fundam Clin Pharmacol. 2007; 21(6): 567-74.

Cagni P, Barros M. Cannabinoid type 1 receptor ligands WIN 55,212-2 and AM 251 alter anxiety-like behaviors of marmoset monkeys in an open-field test. Behav Brain Res. 2013; 240: 91-94

Candland DK, Nagy ZM. The open field: some comperative data. Annals New York Academy of Sciences. 1969; 159: 831-851.

Carobrez AP, Bertoglio LJ. Ethological and temporal analyses of anxiety-like behavior: The elevated plus-maze model 20 years on. Neuroscience and Biobehavioral Reviews. 2005; 29: 1193-1205.

Crawley J, Goodwin FK. Preliminary report of a simple animal behavior model for the anxiolytic effects of benzodiazepines. Pharmacol Biochem Behav. 1980; 13(2):167-170.

Ehrlich A, Burns N. Exploratory behaviour of the black footed ferret. Canadian Journal of psychology. 1958; 12: 235-241.

Fiset C, Rioux FM, Surette ME, Fiset S. Prenatal Iron Deficiency in Guinea Pigs Increases Locomotor Activity but Does Not Influence Learning and Memory. PLoS One. 2015; 10(7): 0133168.

Hall CS. Emotional behavior in rat: Defaction and urination as measure of individual diffirences in emotionality. Journal of comparative Psychology. 1934; 18: 385-403.

Handley SL, Mithan S. Effects of alpha-adrenoceptor agonists and antagonists in a maze-exploration model of 'fear'-motivated behaviour. Naunyn Schmiedebergs Arch. Pharmacol. 1984; 327:1-5.

Imaizumi M, Miyazaki S, Onodera K. Effects of xanthine derivatives in a light/dark test in mice and contribution of adenosine receptors. Methods Find. Exp. Clin. Pharmacol. 1994; 16: 639-644.

Kalueff AV, Tuohımaa P. Experimental modeling of anxiety and depression. Acta Neurobiol Exp. 2004; 64: 439-448.

Korte SM, De Boer SF. A robust animal model of state anxiety: fear-potentiated behaviour in the elevated plus-maze. Eur J Pharmacol. 2003; 463(1-3): 163-175.

Kumar V, Bhat ZA, Kumar D. Animal models of anxiety: a comprehensive review. 2013; 68(2): 175183.

Martinek Z, Lat J. Long term stability of individual differences in exploratory behavior and rate of habituation in dogs. Physiol Bohemoslov. 1969; 18: 217-225. 
Meijer E, Van Nes A, Back W, Van Der Staay FJ. Clinical effects of buprenorphine on open field behaviour and gait symmetry in healthy and lame weaned piglets. Vet J. 2015; 206(3): 298-303.

Montgomery KC. The relation between fear induced by novel stimulation and exploratory behavior. J Comp Physiol Psychol. 1955; 48(4): 254-260.

Mushtaq MY, Marçal RM, Champagne DL, Van Der Kooy F, Verpoorte R, ChoI YH. Effect of acute stresses on zebra fish (Danio rerio) metabolome measured by NMR-based metabolomics. Planta Med. 2014; 80(14): 1227-1233.

Oldham J, Morlock H. The effects of open field size on activity in the mongolian gerbil. Psycohonomic Science. 1970; 20: 290.

Pedernera-Romano C, Ruız De La Torre JL, Badiella L, Manteca X. Effect of perphenazine enanthate on open-field test behaviour and stress-induced hyperthermia in domestic sheep. Pharmacol Biochem Behav. 2010; 94(3): 329-332.

Pellow S, Chopin P, File SE, Briley M. Validation of open: closed arm entries in an elevated plus-maze as a measure of anxiety in the rat. J. Neurosci Methods. 1985; 14: 149-167.

Porsolt RD, Le Pichon M, Jalfre M. Depression: a new animal model sensitive to antidepressant treatments. Nature. 1977; , 266(5604): 730-732.

Porsolt RD, Anton G, Blavet N, Jalfre M. Behavioural despair in rats: a new model sensitive to antidepressant treatments. Eur J Pharmacol. 1978a; 47(4): 379-391.

Porsolt RD, Bertın A, Jalfre M. "Behavioural despair" in rats and mice: strain differences and the effects of imipramine. Eur J Pharmacol. 1978b; 51: 291-294.

Prut I, Belzung C. The open field as a paradigm to measure the effects of drugs on anxiety-like behaviors: a review. European Journal of Pharmacology. 2003; 463: 3-33.

Sayapina NV, Batalova TA, Cha1ka VV et al. Multi-walled carbon nanotubes increase anxiety levels in rats and reduce exploratory activity in the open field test. Dokl Biol Sci. 2015; 464(1): 223-225.

Soubrie P. Open field chez le rat: interrelations entre locomotion exploration et emotivite. J. Pharmacol. 1971; 2: 457-472.

Stahl SM (2015). Stahl'ın Temel Psikofarmakolojisi, Sinirbilimsel Temeli ve Pratik Uygulaması. Ed: Prof.Dr. Tunç Alkın. S. : 388-420.

Wall PM, Messier C. Methodological and conceptual issues in the use of the elevated plus-maze as a psychological measurement instrument of animal anxiety-like behavior. Neurosci Biobehav Rev. 2001; 25(3): $275-286$.

Walsh RN, Cummimis RA. The open-field test A critical review. Psychological Bulletin. 1976; 83: 482504.

Zimbardo PF, Montgomery KC. Effects of free environment rearing upon exploratory behavior. Psychological Repoils. 1957; 3: 589-594. 